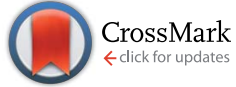

Cite this: RSC Adv., 2016, 6, 25472

DOI: $10.1039 / c 6 r a 90024 k$

www.rsc.org/advances

\title{
Correction: Removal of safranin-O dye from aqueous solution using modified red mud: kinetics and equilibrium studies
}

\author{
Manoj Kumar Sahu and Raj Kishore Patel*
}

Correction for 'Removal of safranin- $O$ dye from aqueous solution using modified red mud: kinetics and equilibrium studies' by Manoj Kumar Sahu et al., RSC Adv., 2015, 5, 78491-78501.

The authors regret that incorrect safranin-O dye adsorption values were presented for the reported adsorbent throughout the original manuscript. Due to these errors, the reported performance of the adsorbent is not representative of its actual performance. The following sections of the original manuscript therefore require amendment.

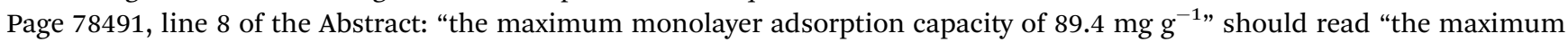
monolayer adsorption capacity of $8.94 \mathrm{mg} \mathrm{g}^{-1 "}$.

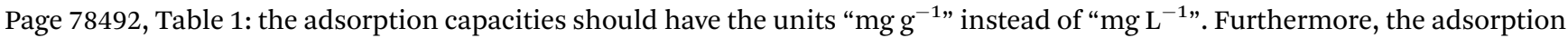
capacity of SDS/RM (present study) in Table 1 should read "8.94" rather than "89.4".

Page 78499, Table 5, Langmuir isotherm model $q_{\mathrm{m}}\left(\mathrm{mg} \mathrm{g}^{-1}\right)$ values at $308 \mathrm{~K}, 318 \mathrm{~K}$ and $328 \mathrm{~K}$ : "89.471", "84.193" and "79.423" should read "8.9471", "8.4193" and "7.9423", respectively.

Page 78499, Table 5, Dubinin-Radushkevich isotherm model $q_{\mathrm{m}}\left(\mathrm{mg} \mathrm{g}^{-1}\right)$ values at $308 \mathrm{~K}, 318 \mathrm{~K}$ and $328 \mathrm{~K}$ : "80.927", "74.890" and "69.254" should read "8.0927", "7.4890" and "6.9254", respectively.

Page 78499, Table 5, Elovich isotherm model $q_{\mathrm{m}}\left(\mathrm{mg} \mathrm{g}^{-1}\right)$ values at $308 \mathrm{~K}, 318 \mathrm{~K}$ and $328 \mathrm{~K}$ : “17.397”, “27.571" and "37.230" should read "1.7397", "2.7571" and "3.7230", respectively.

Page 78500 , line 11 of the Conclusions: " $89.471 \mathrm{mg} \mathrm{g}^{-1}$ " should read " $8.94 \mathrm{mg} \mathrm{g}^{-1 "}$ ".

Additionally, a citation to the authors' previous work on a modified red mud dye adsorbent was omitted from the original article. ${ }^{1}$ The relevant reference is presented herein, to provide a more complete overview of the existing literature.

The Royal Society of Chemistry apologises for these errors and any consequent inconvenience to authors and readers.

\section{References}

1 M. K. Sahu, U. K. Sahu and R. K. Patel, RSC Adv., 2015, 5, 42294-42304. 